\title{
“E O LAZER NA CONSTRUÇÃO DO JOGO DO SABER?? NINGUÉM SABE, NINGUÉM VIU!!!"
}

Recebido em: 06/02/2017

Aceito em: 18/10/2017

Débora Alice Machado da Silva Mário Hiago de Souza

Escola Superior de Educação Física (ESEF)

Jundiaí - SP - Brasil

RESUMO: A difusão das Escolas de Tempo Integral impõe a reflexão sobre a ampliação da jornada escolar repensando toda a dinâmica do uso dos tempos dos espaços e dos objetivos que lhe são constitutivos. Nesse trabalho analisamos de que maneira a temática do lazer aparece no Projeto Político-Pedagógico (PPP) de escolas de Tempo Integral do Município de Jundiaí-SP, buscando compreender suas implicações para a garantia do direito ao lazer, em sua relação com a educação. Tratase de uma pesquisa de campo qualitativa realizada por meio da análise do PPP a partir de determinadas categorias. $O$ estudo aponta para necessidade de uma maior reflexão acerca do lazer na construção dos PPPs, tendo em vista sua estreita relação com a vida cultural da sociedade e dos territórios em que as escolas estão situadas, mas do que isso pelo lazer se configurar como uma possibilidade de formação e participação cidadã.

PALAVRAS CHAVE: Atividades de Lazer. Educação. Projetos.

\section{WHERE IS LEISURE IN THE CONSTRUCTION OF THE KNOWLEDGE GAME? NOBODY KNOWS, NOBODY SAW!}

ABSTRACT: The diffusion of the Schools of Integral Time imposes the reflection on the amplification of the school day rethinking all the dynamics of the use of the times, the spaces and the objectives that are constituent to him. In this work, we analyze how the theme of leisure appears in the Political-Pedagogical Project (PPP) of Integral Schools of the Municipality of Jundiaí-SP, seeking to understand its implications for the guarantee of the right to leisure, in its relationship with education. It is a qualitative field research carried out through the analysis of PPP from certain categories. The study points to the need for a greater reflection on leisure in the construction of PPPs, considering their close relationship with the cultural life of society and the territories in which the schools are located, but rather for leisure as a possibility Training and citizen participation.

KEYWORDS: Leisure Activities. Education. Projects. 


\section{Introdução}

As Escolas (de Tempo) Integral ${ }^{1}$ têm crescido de maneira significativa nos últimos anos, por meio de políticas públicas induzidas pelo governo federal. Pensar como o lazer está presente nessas discussões é indispensável, já que as crianças chegam a ter uma jornada de nove horas diárias dentro das escolas, mas, principalmente, pelo fato de que o lazer possui estreita ligação com a vida cultura da sociedade e da comunidade a qual a escola pertence, portanto com o mundo vivido pelos alunos.

Da mesma forma, ao considerarmos que a Educação Física trata da Cultura Corporal de Movimento é imprescindível que possamos compreender suas contribuições com propostas que visem a uma Educação Integral em Tempo Integral, explicitando também seu compromisso com a garantia dos direitos das crianças.

A escolha desse tema foi decorrente de algumas leituras realizadas por conta própria ao longo do curso de educação física na ESEF-Jundiaí que permitiram conhecer a temática do lazer e compreender suas possíveis relações com a educação, ampliando nosso entendimento sobre esse campo no que diz respeito a seus fundamentos e seus conceitos, bem como reconhecendo suas possibilidades de prática e de atuação profissional, que não se restringem à Educação Física.

O lazer passa a ser considerado como um direito social do cidadão a partir da Constituição de 1988, mas continua ausente das propostas educacionais nas escolas ou, quando presente, aparece visando o controle social ou com uma concepção de caráter assistencialista.

\footnotetext{
${ }^{1} \mathrm{O}$ uso do termo Escola (de Tempo) Integral aqui faz referência ao formato que vem sendo implementado, em que o contra turno reproduz as características do turno escolar e, neste sentido, explicita a ausência de um debate mais amplo sobre os usos dos tempos e dos espaços, bem como dos objetivos escolares do tempo integral, negligenciando o compromisso com uma Educação Integral em Tempo Integral.
} 
O aumento das Escolas (de Tempo) Integral que, no discurso, se propõem a uma educação integral, deveria contemplar uma reflexão sobre a importância do lazer como uma dimensão da vida dos alunos. Isso é reforçado pelo fato do lazer ser previsto por lei como um direito social vinculado à formação cidadã, como expresso no Estatuto da Criança e do Adolescente - ECA (BRASIL, 1990).

É com base nesse conjunto de elementos que o presente trabalho buscou compreender de que forma a temática do lazer é tratada pelas Unidades Escolares de Tempo Integral no município de Jundiaí-SP, especificamente em seus Projetos PolíticoPedagógicos.

\section{Objetivo}

Analisar de que maneira a temática do lazer aparece no Projeto PolíticoPedagógico de Escolas de Tempo Integral do Município de Jundiaí-SP, buscando compreender suas implicações para a garantia do direito ao lazer previsto na Constituição e no Estatuto da Criança e do Adolescente, bem como suas implicações para atuação dos professores, em particular os de educação física.

\section{A Escola (de Tempo) Integral e o Direito das Crianças ao Lazer}

As escolas (de tempo) integral têm crescido de maneira significativa por meio de políticas públicas induzidas pelo do Governo Federal nos últimos anos. O documento que apresenta as 20 metas do Plano Nacional de Educação - PNE 2014/2024 (BRASIL, 2014) distingue três tipos de metas: aquelas que têm o papel de reduzir a desigualdade e valorizar a diversidade em busca da equidade; as metas 
orientadas a valorização dos profissionais da educação e aquelas que são estruturantes para a garantia do direito à educação básica com qualidade.

Entre estas últimas encontramos a Meta 6 que diz respeito a oferta de educação integral em, no mínimo, 50\% das escolas públicas de forma a atender pelo menos 25\% dos (as) alunos (as) da educação básica. Portanto, considerando o PNE, a Educação Integral passa a se configurar como uma prioridade para a próxima década no Sistema Nacional de Educação.

Com vistas a ampliar as estratégias para viabilizar essa Meta, o governo federal instituiu por meio do Decreto $\mathrm{n}^{\circ} 7.083$, de janeiro de 2010, o Programa Mais Educação cuja finalidade expressa em seu artigo $1^{\circ}$ é:

[...] contribuir para a melhoria da aprendizagem por meio da ampliação do tempo de permanência de crianças, adolescentes e jovens matriculados em escola pública, mediante oferta de educação básica em tempo integral.

$\S 1^{\circ}$ Para os fins deste Decreto, considera-se educação básica em tempo integral a jornada escolar com duração igual ou superior a sete horas diárias, durante todo o período letivo, compreendendo o tempo total em que o aluno permanece na escola ou em atividades escolares em outros espaços educacionais.

$\S 2^{\mathrm{o}}$ A jornada escolar diária será ampliada com o desenvolvimento das atividades de acompanhamento pedagógico, experimentação e investigação científica, cultura e artes, esporte e lazer, cultura digital, educação econômica, comunicação e uso de mídias, meio ambiente, direitos humanos, práticas de prevenção aos agravos à saúde, promoção da saúde e da alimentação saudável, entre outras atividades.

$\S 3^{\circ}$ As atividades poderão ser desenvolvidas dentro do espaço escolar, de acordo com a disponibilidade da escola, ou fora dele sob orientação pedagógica da escola, mediante o uso dos equipamentos públicos e do estabelecimento de parcerias com órgãos ou instituições locais.

A ideia de uma educação integral não nasce de experiências inovadoras do século XXI. Muito antes disso, aqui no Brasil, Anísio Teixeira, inspirado nas ideias do 
filósofo e pedagogo norte-americano, John Dewey, já abria caminhos para a veiculação dessa concepção de educação (GADOTTI, 2009). Para Teixeira (1962) a escola deveria fornecer uma ampliação da jornada escolar, o acréscimo de atividades educativas de diversas naturezas, assim como a preparação de um novo professor para atuar nessa escola.

Anísio Teixeira (1962) não apenas escreveu sobre essa concepção de educação, mas concretizou suas propostas na construção do "Centro de Educação Primária Carneiro Ribeiro", que viria a servir de modelo para outros Centros no Estado da Bahia. Essa iniciativa previa o tempo de permanência da criança na escola das $7 \mathrm{~h} 30$ às 16h30, sendo quatro horas destinadas às atividades realizadas nas Escolas-Classe, uma hora de almoço e outras quatro horas seriam dedicadas às atividades nas EscolasParque, um "conjunto de edifícios de atividades de trabalho, sociais, de educação física e de arte" no qual "predomina o sentido de atividade completa".

Outra iniciativa, inspirada nos ideais de Anísio Teixeira, de escola de tempo integral que forneça atividades diversificadas a nível cultural, científico, artístico, foi retomada por Darcy Ribeiro² (GADOTTI, 2009). Seguindo os princípios de educação integral, Darcy Ribeiro, enquanto vice-governador do Estado do Rio de Janeiro na Gestão do Governador Leonel Brizola (1983-1987) idealizou e realizou a construção dos CIEP's (Centros Integrados de Educação Pública). A possibilidade de convivência

\footnotetext{
${ }^{2}$ Anísio Teixeira e Darcy Ribeiro trabalharam juntos na fundação da Universidade Federal de Brasília (UnB). Coube a Darcy Ribeiro a definição das bases da instituição e a Anísio Teixeira o desenvolvimento do plano pedagógico, tendo ainda a colaboração de Oscar Niemeyer no projeto arquitetônico. O projeto da construção da Universidade foi definido por uma espécie de Carta Magna que explicitava a promessa de "reinventar a educação superior, entrelaçar as diversas formas de saber e formar profissionais engajados na transformação do país" (UnB, 2008 - site da Universidade $<$ http://www.unb.br/sobre/principais_capitulos/criacao $>$ ) Retomamos esse histórico a fim de afirmar a afinidade entre Anísio Teixeira e Darcy Ribeiro no sentido de justificar a afirmação de que os CIEP's recuperam, em certo sentido, os ideais das Escolas Parque, tendo em vista que alguns pesquisadores insistem em considerar essa aproximação equivocada. Em nosso entendimento, as afinidades e compromissos expressos na Carta Magna de Brasília nada mais eram do que o ponto de partida vislumbrado por seus autores visando transformações mais profundas da educação brasileira.
} 
familiar e comunitária seria potencializada por uma escola pensada como "centro de cultura" numa perspectiva de fazê-las interagir fecundamente (RIBEIRO, 1995). Para a concretização deste propósito

[...] foi criada uma posição especial no seu quadro profissional: a dos Animadores Culturais, que relacionam a escola com seu contexto, oferecendo as facilidades com que ela conta - estádio esportivo, biblioteca, salão social e refeitório - para o uso comunitário, sobretudo nos dias em que não tem aula. (p.2)

Os direitos ao lazer, ao brincar também são garantidos pelo ECA (BRASIL, 2015) nos artigos:

Art. $4^{\circ}$ - É dever da família, da comunidade, da sociedade em geral e do poder público assegurar, com absoluta prioridade, a efetivação dos direitos referentes à vida, à saúde, à alimentação, à educação, ao esporte, ao lazer, à profissionalização, à cultura, à dignidade, ao respeito, à liberdade e à convivência familiar e comunitária (p.11).

Art. $15^{\circ} \mathrm{A}$ criança e o adolescente têm direito à liberdade, ao respeito e à dignidade como pessoas humanas em processo de desenvolvimento e como sujeitos de direitos civis, humanos e sociais garantidos na Constituição e nas leis (p. 12).

Art. $16^{\circ} \mathrm{O}$ direito à liberdade compreende os seguintes aspectos: I - ir, vir e estar nos logradouros públicos e espaços comunitários, ressalvadas as restrições legais;

II - opinião e expressão;

III - crença e culto religioso;

IV - brincar, praticar esportes e divertir-se;

$\mathrm{V}$ - participar da vida familiar e comunitária, sem discriminação;

VI - participar da vida política, na forma da lei;

VII - buscar refúgio, auxílio e orientação.

Art. 59 - Os municípios, com apoio dos estados e da União, estimularão e facilitarão a destinação de recursos e espaços para programações culturais, esportivas e de lazer voltadas para a infância e a juventude (p.21).

Art. $71^{\circ}$ - A criança e o adolescente têm direito a informação, cultura, lazer, esportes, diversões, espetáculos e produtos e serviços que respeitem sua condição peculiar de pessoa em desenvolvimento (p.22). 
Por outro lado, fundamentando a reflexão em Silva (2014) é necessário considerarmos que a realidade de significativa parcela das crianças brasileiras está muito distante dos direitos que lhes são previstos na legislação mais recente do ECA. Nesse sentido, as políticas públicas voltadas para as crianças deveriam comprometer-se com a criança em seu contexto de vida concreto, para que não ocorra a distorção entre a imagem real e a ideal — da criança que brinca e frui de seu direito ao lazer sendo, assim, respeitada em sua condição de cidadão. Dessa perspectiva as políticas públicas seriam formas de ação e inação do Estado no sentido de se opor ou afirmar as “imagens reais de exploração, alienação, trabalho, adestramento físico e moral que respondam à lógica hegemônica da nossa sociedade" (SILVA, 2014, p. 109).

A autora afirma ser fundamental considerar, ao tratar a criança como sujeito de direitos, a questão da ampliação dos canais de participação social que não podem se restringir apenas ao direito ao voto (permitido à maiores de 16 anos). Marcellino (2005) considera que a participação cultural pode se constituir como uma forma de participação social e de participação cultural, portanto uma experiência da cidadania.

Diante de tais questões, emerge a necessidade de realizar a tarefa da reflexão sobre qual é a função social da escola. Quais seus sentidos e significados na atualidade considerando que todos esses aspectos são atravessados por diferentes visões políticas, ideológicas e seus diversos e contraditórios interesses?

Nesta pesquisa pensamos a educação escolar conforme Gadotti (2009) entendendo que a formação humana integral deve ser "vista sob uma perspectiva holística" (p.41), por meio de uma educação que não fragmente a construção do conhecimento com a "educação emocional e da construção para a cidadania" (p.41). 
A discussão em torno da educação integral, e que estaria melhor contemplada nos moldes de tempo integral, não é um debate atual. Gadotti (2009, p. 32) nos adverte para o fato de que estas propostas têm se destinado a "estender o direito de passar mais tempo na escola às camadas pobres da população", sem propostas muito claras e objetivas, articuladas ao Projeto Político-Pedagógico para a construção da cidadania. O que reafirma perspectivas assistencialistas e de controle social.

Gadotti (2009) nos lembra que a extensão da jornada escolar para o tempo integral não necessariamente caracterizará uma educação integral. Nessa concepção, torna-se papel fundamental e indispensável da escola, o fornecimento de uma diversidade de aprendizagens que dê conta de abranger os múltiplos interesses dos alunos.

Segundo Gadotti (2009) estas aprendizagens diversificadas do teatro, da música, da dança etc., devem levar em conta toda a comunidade do entorno, valorizando a cultura local e a participação cultural da comunidade local e escolar. Essa comunidade deve ser entendida, conforme afirma o autor, não somente enquanto as pessoas que a compõem, como os pais, comerciantes, ONGs, movimentos sociais etc., devendo levar em conta ainda os espaços físicos presentes nesse entorno, como clubes, praças, teatro, museu, cinema etc.

As Diretrizes Curriculares Nacionais para a Educação Básica (BRASIL, 2013) apontam a Educação em Tempo Integral como o caminho para superação de grandes desigualdades sociais que o país enfrenta mas esses termos precisam ser problematizados.

As diretrizes orientam a realização de atividades além dos muros escolares, utilizando outros espaços públicos, mas também advertem para a obrigatoriedade dos 
órgãos executivos responsáveis pela Educação garantirem condições estruturais e infraestruturais e, principalmente, que tudo esteja ancorado num processo contínuo de formação e valorização do magistério com vistas ao desenvolvimento deste processo. Para dar continuidade a nossos apontamentos recuperamos a seguinte reflexão de Silva (2014, p.107).

A prioridade absoluta dada à criança no que se refere ao direito à educação significa exatamente o que? Que ela tem direito a escola? Mas que escola é essa que se ancora num vir-a-ser que muitas vezes não é, desconsiderando que as crianças SÃO (no presente) em seus tempos e espaços historicamente situados? Em uma conjuntura global marcada pela precarização das relações de trabalho e pelo desemprego estrutural, onde é difícil fazer projeções de longo prazo, a escola que prepara o vir-a-ser idealizado tem seu lugar? Nossa resposta é sim, se ela se transformar numa "instituição total" (GOFFMAN, 2001) que sirva ao controle social. Mas, não é essa a escola que queremos ou acreditamos.

\section{E o Lazer na Construção do Jogo do Saber?}

A escola privilegiou e em grande medida ainda privilegia a formação orientada à dimensão da vida profissional “em nome da 'produtividade' da sociedade moderna como um todo" (MARCELLINO, 1988, p. 60).

Essa concepção fragmentária não pode estar vinculada a uma educação progressista, como afirma Marcellino (2000), a respeito de uma formação que engloba valores de cidadania e envolve uma formação para o trabalho. Não se pode esquecer que o lazer é uma possibilidade de exercício de cidadania podendo contribuir com o desenvolvimento pessoal e social.

A não legitimidade atribuída ao lazer não se esgota no nível escolar, mas também faz parte do imaginário da sociedade como um todo. Explicitar o entendimento de lazer que assumimos é necessário para não cairmos no reducionismo de compreendê-lo, como adverte Marcellino (2005, p.24), apenas como um mero 
divertimento, ou descanso, vinculado a valores conservadores que reproduzem um lazer enquanto "fuga, fonte de alienação e consumo".

O lazer na escola, pensado de uma perspectiva contrária a lógica dos valores hegemônicos, tem de ser entendido de maneira mais ampla, como afirma Marcellino (2000), como um tempo, um espaço e também o desenvolvimento da atitude pessoal para sua fruição. Dessa forma, não pode ser aceito enquanto alguns eventos isolados ou a simples presença de alguns conteúdos, mas enquanto "produto e processo" (MARCELLINO, 2005, p.28).

O desenvolvimento da atitude pessoal dos alunos apontado por Marcellino (2005) se refere à garantia de informações específicas a respeito do lazer e de seus conteúdos, a valorização do lazer enquanto uma dimensão da vida e a iniciação aos seus conteúdos culturais.

Os conteúdos culturais do lazer são descritos por Marcellino (2000), por meio dos seguintes interesses que movem as pessoas: físicos-esportivos, manuais, artísticos, intelectuais, turísticos e sociais. Essa diversidade de conteúdos poderia nortear às propostas educacionais na perspectiva de construção de um currículo mais humano, integral e cidadão. Afinal, não podemos confundir orientação e motivação com um simples “deixar fazer” (MARCELLINO, 1988, p.64).

Para dar conta de uma formação cultural diversificada e, porque não dizer, integral, seria necessário repensar os tempos e os espaços escolares. A escola dividida em turnos necessita repensar e problematizar esses tempos, assim como os objetivos da Escola Integral de Tempo Integral. Da mesma forma, se faz necessário o repensar dos espaços escolares no sentido de transcender os muros escolares para os outros espaços da comunidade em que a escola está inserida visando um melhor aproveitamento dos 
espaços existentes no entorno, buscando favorecer o vínculo escola-comunidade (MARCELLINO, 2000).

A presença do lazer no projeto político-pedagógico da escola, sendo ele um direito social e a partir do esclarecimento de sua legitimidade, deve ser pensada e realizada de maneira séria, crítica e consciente de modo que não venha a "disfarçar incompetências técnicas ou falta de recursos, sem discursos desvinculados da prática" (MARCELLINO, 1988, p.70). Nesse sentido, a escola continuaria comprometida com a socialização dos saberes e conhecimentos historicamente produzidos pela humanidade, como aponta Silva (2014).

\section{Lazer e Educação Física}

A Educação Física Escolar sempre esteve alicerçada nas ciências biológicas, o que lhe conferiu um trato sobre o corpo e o movimento a partir de uma perspectiva que não valoriza o aspecto cultural. Nessa perspectiva, qualquer relação que se possa fazer entre lazer e educação física escolar se torna inviável, pois o foco se mantém no desenvolvimento motor (BETTI, 2009).

Compreender a Educação Física para além do trato com o desenvolvimento motor significa, como nos lembra Betti (2009, p.156), entendê-la como "uma área de conhecimento e intervenção profissional-pedagógica que lida com a cultura corporal de movimento". Isso confere à Educação Física Escolar enquanto um componente curricular: "propiciar aos alunos a apropriação crítica da cultura corporal de movimento, associando organicamente "o saber movimentar-se" ao "saber sobre" esse movimentar-se". 
A Educação Física Escolar não estaria mais compromissada com o desenvolvimento motor de um corpo desculturalizado (BETTI, 2009), da mesma forma que deve desvencilhar-se de valores hegemônicos tradicionais na área como “treinamento pré-militar, eugenia, nacionalismo, preparação de atletas etc.” (BETTI e ZULIANI, 2002, p.2). Desse modo, como afirmam Betti e Zuliani (2002, p.5), a Educação Física Escolar deve garantir aos alunos a oportunidade de aprendizagem dos elementos da cultura corporal de movimento de maneira diversificada por meio de “jogos, esporte, atividades rítmicas/expressivas e dança, lutas/artes marciais, ginásticas e práticas de aptidão física, com suas variações e combinações" tendo por finalidade que esses alunos se apropriem destes elementos, que podem ser usados como práticas em seus momentos de lazer.

Assumindo essa perspectiva a Escola de Tempo Integral teria a seu dispor, no que diz respeito à Educação Física, os elementos da cultura corporal de movimento como complemento de uma Educação Integral para além das aulas do currículo comum, podendo ser estabelecidos, junto às demandas da comunidade escolar e do entorno como um todo, projetos e oficinas específicas relacionais à cultura local, considerando ainda a possibilidade das oficinas relacionadas ao esporte.

Ao considerar a Educação Física Escolar como aquela que trata dos elementos da cultura corporal de movimento, cabe refletir sobre esse termo "cultura". De acordo com Silva e Silva (2012, p.32) a "cultura é categoria central para a área, sendo o principal contraponto à visão biológica de corpo humano". Isso nos permite contrapor aquilo que é universal no ser humano daquilo que é construído a partir de determinados grupos culturais que atribuem diferentes sentidos e significados às manifestações corporais. 
Ainda seguindo a linha das autoras, compreender os fenômenos sociais do lazer e da Educação Física a partir da cultura enquanto algo "eminentemente humano" (p.63) nos fornecerá mais elementos para atuar em diferentes contextos socioculturais, por intermédio da cultura corporal de movimento, selecionando as manifestações corporais que possuem maior valor simbólico para uma determinada comunidade.

Outro avanço obtido em termos de compreensão da importância da educação física estar presente na escola é a sua alocação no documento preliminar da Base Curricular Nacional Comum do Governo Federal, que se encontra na sua segunda versão em fase de aprovação, na área de conhecimento das linguagens, ao lado de Língua Portuguesa, Língua Estrangeira Moderna e Arte (BRASIL, 2015). São variadas as formas que as linguagens permitem expressão como "a verbal, a corporal, a musical, a visual, etc.” (p. 22).

De acordo com o documento da Base Nacional Comum Curricular (BRASIL, 2015, p. 30), a área de conhecimento das linguagens deve ser compreendida como uma maneira de refletir como o ser humano "se constitui como sujeito e age no mundo social em interações mediadas por palavras, imagens, sons, gestos e movimentos". Essas ações sobre o mundo social podem ocorrer por meio das práticas corporais, pois estas permitem aos sujeitos irem "constituindo subjetividades e identidades, quer seja na dimensão do lazer, quer seja na dimensão da saúde.” (BRASIL, 2015, p.97).

Vale ressaltar que não podemos atribuir somente às disciplinas historicamente tratadas como menos importantes e secundárias, como é o caso da Educação Física e das Artes, o papel de dar conta desses elementos relativos ao lazer. A partir da diversidade dos conteúdos culturais do lazer, qualquer disciplina poderia estar contemplada em algum desses conteúdos de modo a dar conta dos elementos referentes 
ao lazer. É essencial que haja a incorporação do lazer por parte do PPP abrangendo todas as pessoas envolvidas no processo de educação escolar.

A relação entre Lazer e Educação Física foi destacada neste trabalho não pelo fato dessa articulação ser direta, ou a única possível desconsiderando a contribuição de professores com outras formações, mas pelo fato de que, tratando-se de um Trabalho de Conclusão de Curso sob a titulação de Licenciatura em Educação Física, procurouse refletir sobre as particularidades referentes a estas áreas: Lazer e Educação Física.

\section{Metodologia}

Primeiramente a intenção da pesquisa era avaliar o Projeto Político-Pedagógico (PPP) de quatro Escolas (de Tempo) Integral, identificadas no documento "A Escola de Tempo Integral da prefeitura de Jundiaí” (JUNDIAÍ, 2012).

As escolas com as quais fizemos contato para a participação na pesquisa se mostraram prestativas no sentido do fornecimento do PPP para análise e participação da pesquisa, disponibilizando por e-mail ou autorizando que se fotografasse o documento.

As primeiras leituras trouxeram à tona alguns limites de nosso propósito inicial, que era avaliar o PPP de quatro unidades escolares.

Diante das particularidades encontradas no documento de cada unidade e do tempo que seria necessário para fazer uma análise que não fosse superficial, fizemos a opção de analisar apenas um dos projetos político-pedagógicos de maneira a nos familiarizarmos com a estrutura do documento, fazendo o esforço de reconhecer suas particularidades para, em outro momento, voltar aos outros PPP com um olhar mais apurado para as questões que levantamos. 
Dessa forma, o trabalho consistiu em uma pesquisa de campo qualitativa que foi realizada por meio da análise do PPP de uma escola. A escolha da escola a ser analisada, entre as dez Escolas (de Tempo) Integral atualmente existentes, identificadas no documento "Proposta Curricular Ensino Fundamental 2016" Jundiaí (2016), pertencentes a Rede Municipal de Jundiaí-SP, foi pautada pelos seguintes critérios:

1- Maior tempo de funcionamento como escola de tempo integral: optou-se por escolher uma escola que tivesse maior tempo de atuação por entender que essa possa ter um projeto mais consolidado.

2- Menor quantidade de alunos: entendendo que por apresentar menor quantidade de alunos, seria menos complexa a organização da escola.

3- Acessibilidade do pesquisador.

\section{Análise dos Dados}

Ao analisar o documento mediante a leitura sistematizada, procurou-se verificar como o lazer estava sendo abordado, levando em conta as seguintes categorias:

1- Abordagem direta ou indireta (MARCELLINO, 2000): a abordagem indireta se dá quando o PPP é enfatizado apenas nos seus conteúdos culturais ou quando é determinado por caráter de obrigatoriedade. Na abordagem direta ele é compreendido na sua especificidade, que envolve os conteúdos culturais, porém abrange também a no lazer, o tempo disponível, os valores propiciados pela prática e seus aspectos educativos, sendo entendido como manifestação humana.

2- Caracterização da comunidade: esse aspecto é analisado sob o olhar que o documento apresenta em relação ao mapeamento das potencialidades culturais 
e lúdicas que a comunidade na qual a escola está inserida pode ofertar de modo a garantir o direito ao lazer. Essa caracterização pode ser expressa por meio das pessoas que ali residem (grupos organizados) e também mediante o levantamento de outros espaços disponíveis para além dos muros da escola, aquilo que Marcellino (2000) chama de equipamentos para a prática do lazer (específicos e não específicos), de maneira a realizar uma cartografia cultural do território.

3- Formação cultural da comunidade escolar: refere-se ao mapeamento da formação cultural das pessoas envolvidas no cotidiano escolar (direção, coordenação, funcionários, professores, apoiadores, voluntários)

4- Componentes curriculares: alguns conteúdos podem estar mais associados à ludicidade, ao prazer como é o caso das disciplinas de Educação Física e Artes, porém há que se fazer uma ressalva, pois o lazer enquanto manifestação humana pode fazer interface com qualquer componente curricular.

5- Componentes extracurriculares: normalmente, as escolas estão organizadas em Base Comum num período, e as oficinas/projetos em outro período. O chamada contra turno tem por característica o oferecimento de atividades diversificadas de caráter cultural.

\section{Tópico 1: Abordagem Direta ou Indireta}

O que se pôde observar por meio da análise do PPP é que o termo lazer aparece de maneira indireta, não sendo conceituado ou mencionado como um direito social em nenhum momento. Ele aparece representado mediante seus conteúdos culturais disponibilizados em forma de oficinas. 
Em uma passagem do PPP (JUNDIAÍ, 2015, p.6) que diz:

[...] não basta garantir a permanência do aluno na escola em tempo integral; é preciso fazer com que esta escola, além de cumprir sua função de transmitir os saberes sistematizados produzidos pela humanidade, possa ao mesmo tempo, ser espaço de expressão da alegria.

É possível verificar uma tentativa, ainda que singela, de aproximação do lazer, porém, falar em alegria não significa que o lazer se faça presente, afinal de contas a alegria pode estar presente no trabalho, nas obrigações familiares e sociais, mas isso não significa estar em um momento de lazer, pois a categoria tempo não estaria sendo contemplada.

\section{Tópico 2: Caracterização da Comunidade}

O documento não faz nenhuma menção a possíveis grupos culturais organizados presentes no bairro. No trecho em que aparecem as características das pessoas que vivem no entorno da escola, são apresentadas apenas as categorias profissionais dos habitantes sendo eles “médicos, engenheiros, pequenos empresários, gerente de banco, secretárias, comerciantes, operários, funcionários públicos, entre outros" (JUNDIAÍ, 2015, p.58).

Com relação aos espaços do entorno, o mapeamento realizado verificou a existência de um "viveiro de plantas da prefeitura de Jundiaí (Unidam), Maxi Shopping, padaria, pet shop, farmácia, oficinas mecânicas, autoelétricas, gráficas, salão de cabeleireiro e manicure/pedicure, minimercados, igreja Católica, igreja Evangélica e Centro Espírita.” (JUNDIAÍ, 2015, p. 58). Porém no documento não fica explícita a possibilidade de utilização dessas potencialidades do bairro no sentido de ampliação das vivências culturais, assim como o mapeamento de possíveis áreas ociosas em alguns períodos que pudessem ser aproveitadas pela escola, pois, de acordo com 
Marcellino (2000), espaços que a princípio não são específicos para a prática do lazer podem ser utilizados com esse objetivo.

\section{Tópico 3: Formação Cultural da Comunidade Escolar}

O PPP traz informações sobre as pessoas envolvidas no cotidiano escolar, sejam elas professores, funcionários, coordenadores, diretor no que se refere ao nível de escolaridade concluída e habilitação para as áreas de atuação. Porém, não faz menção a formação cultural (em uma perspectiva mais ampla) das pessoas envolvidas que poderiam ser aproveitadas como potencialidades para proporcionar atividades diversificadas, contribuindo de diferentes maneiras na construção do Projeto Político Pedagógico.

\section{Tópico 4: Componentes Curriculares}

Com relação aos componentes curriculares (Língua Portuguesa, Arte, Educação Física, Matemática, Ciências Físicas e Biológicas, História e Geografia) a única proposta que se encontra explícita no documento (PPP) é a da Educação Física, ou seja, um olhar a respeito de como o lazer pode ser abordado nos componentes curriculares só aparecem na proposta da educação física. Assim mesmo, o documento menciona o lazer e não vai além disso e de uma aproximação e uso de termos como aprendizado de habilidades motoras e desenvolvimento motor.

Nas expectativas de aprendizagem e conteúdos a serem trabalhados ao longo dos anos em educação física aparecem os diferentes conteúdos da cultura corporal de movimento (jogo, dança, luta, esporte, ginástica), assim como as seguintes colocações que poderiam se aproximar da temática do lazer (JUNDIAÍ, 2016, p. 100-104): 
$1^{\mathrm{o}}$ ano (p.100)

Expectativa de aprendizagem: diferenciar o tempo social da criança.

Conteúdos: direito da criança ao tempo do brincar.

$2^{\circ}$ ano (p.101)

Expectativa de aprendizagem: associar brincadeiras ao tempo social da criança.

Conteúdos: direitos da criança.

$3^{\circ}$ ano (p.102)

Expectativa de aprendizagem: diferenciar tempos sociais

Conteúdos: tempos sociais - trabalho, estudo, descanso, lazer e diversão.

$4^{\circ}$ ano (p.104)

Expectativa de aprendizagem: conceituar, identificar e diferenciar momentos de lazer.

Conteúdos: atividades realizadas no tempo disponível, atividades de livre escolha, recreio, espaços destinados ao lazer - praças, escolas, clubes e centros esportivos.

Nos $1^{\circ}$ e $2^{\circ}$ anos aparece implicitamente e sem aprofundamento o lazer enquanto um direito que permite um tempo social destinado ao brincar. No $3^{\circ}$ ano já aparece explicitamente o termo lazer. No $4^{\circ}$ ano aparece o lazer novamente, agora mais aprofundado citando as categorias de tempo disponível, atividades de livre escolha e também os espaços destinados ao lazer. 


\section{Tópico 5: Componentes Extracurriculares}

No PPP da instituição os componentes extracurriculares estão especificados em diálogo com o documento do Programa "Mais Educação" do Governo Federal que tem por objetivo promover "ampliação de tempos, espaços, oportunidades educativas [...] isso porque a educação integral, associada ao processo de escolarização, pressupõe a aprendizagem conectada a vida e ao universo de interesses e de possibilidades das crianças, adolescentes e jovens" (JUNDIAÍ, 2015, p.137)

Esses componentes estão divididos em dez macro campos, sendo eles: Acompanhamento Pedagógico, Educação Ambiental, Esporte e Lazer, Direitos Humanos e Educação, Cultura e Artes, Cultura Digital, Promoção da Saúde, Comunicação e uso de mídias, Investigação no campo das Ciências da Natureza, Educação Econômica. De acordo com o PPP da escola Jundiaí (2015, p.137) “são escolhidas seis atividades, a cada ano, no universo de possibilidades ofertadas. Uma destas atividades obrigatoriamente deve compor o macrocampo acompanhamento pedagógico". Na escola estudada, as oficinas desenvolvidas ao longo de 2015, foram: "Alfabetização e Letramento", "Língua Portuguesa: ênfase em leitura e produção de texto", "Matemática com Jogos", "Capoeira”, "Esporte”, "Direitos Humanos", "Música".

As oficinas de Alfabetização e Letramento/Produção de texto, Leitura e Matemática com Jogos, estão inclusas no campo de acompanhamento pedagógico. Elas possuem como característica principal o lúdico, utilizando muitos jogos como estratégia de aprendizagem. O lazer e seus conteúdos culturais, no entanto, não aparecem como questão central, os objetivos estão mais voltados para o processo de leitura, escrita e cálculo. 
A oficina de Capoeira faz parte do macrocampo Cultura e Arte tendo por objetivo a difusão de uma prática de relevância cultural. Ainda que não possa ser associada ao lazer por ter caráter obrigatório, a Capoeira é uma prática corporal que pode ser realizada em tempos e espaços fora da escola, com diferentes sentidos para seus praticantes.

A oficina de Música segundo o documento possui caráter de obrigatoriedade pela Lei 11.769/08. A música não deve ser entendida apenas como uma metodologia para trabalhar diferentes conteúdos nas aulas, mas como um fenômeno produzido culturalmente e valorizado pela sociedade como expressão artística, portanto, como uma dada linguagem.

Além das oficinas existem as atividades extraescolares previstas no calendário da escola estudada que foram: Acampamento Timbalaia em Mairiporã para os $1^{\text {os }}, 2^{\text {os }}$, $3^{\text {os }}$ e $4^{\text {os }}$ anos. Os $5^{\text {os }}$ anos visitarão o Hotel Fazenda Solar das Andorinhas em Campinas.

Da mesma forma, a que se considerar as denominadas atividades complementares, de caráter festivo, previstas no calendário escolar, são elas: Baile de Carnaval (fevereiro), Festa de Páscoa e entrega dos ovos de Páscoa (abril), Festa Junina (junho), Festa da Primavera (outubro), Festa das Crianças (outubro), Festa do Halloween, Formatura dos alunos do $5^{\circ} \mathrm{A} / \mathrm{B} / \mathrm{C}$ (dezembro).

As atividades ofertadas enquanto diversificação culturais estão presentes no currículo apontado no PPP. De acordo com os referenciais utilizados na elaboração deste trabalho, acredita-se na possibilidade de ofertar uma maior gama de atividades culturais, naquilo que Marcelino (2000) entende como conteúdos culturais do lazer (físico-esportivo, artístico, manuais, intelectuais, sociais e turísticos). Há que se 
considerar também a possibilidade de livre escolha com relação a qual oficina realizar, mas não se pode ter uma visão romântica, pois cada um só escolhe o que conhece, então é necessário o lado obrigatório visando expandir a formação cultural dos alunos para que eles tenham maior liberdade de escolha.

Marcellino (2005) adverte como o tempo disponível para o lazer poder ser usado como divertimento, descanso e desenvolvimento pessoal e social, o que nos permite considerar algumas questões:

(1) O divertimento pode ocorrer em tempos de obrigações familiares, sociais, profissionais, o que não configura o lazer em sua totalidade. Mas isso não deveria tirar da escola a responsabilidade de abordar a temática considerando que estamos falando de escolas de tempo integral e que o lazer é um dos direitos das crianças.

(2) O divertimento pensado como lazer que demanda tempo e espaço para brincar não aparece sistematizado na rotina escolar. Assim também ocorre com o descanso, considerando o fato de que as crianças passam nove horas por dia na escola e que isso pode se tornar uma rotina exaustiva e estressante para elas.

(3) O lazer não deve ser entendido somente como alívio de tensões ou mero recreacionismo.

Ainda que as dimensões de descansar e divertir-se façam parte do seu entendimento como um todo, o lazer não se esgota nessas dimensões, a par delas devemos considerar o desenvolvimento pessoal e social, como sugere Marcellino (2005), a partir da introdução dos conteúdos culturais do lazer, não somente como vivência, mas como possibilidade de obter conhecimento acerca deles e também de tornar-se um espectador crítico dos conteúdos. 


\section{Considerações Provisórias}

O lazer precisa ser entendido de modo mais crítico e coerente pelos envolvidos na construção do Projeto Político-Pedagógico das unidades escolares tendo em vista o fato de ele ser uma manifestação humana indispensável para a formação integral e uma possibilidade de participação na vida cultural da sociedade, além de um direito social previsto pela Constituição e pelo Estatuto da Criança e do Adolescente.

Ter consciência clara de seus elementos constitutivos (tempo, espaço e atitude) e conteúdos culturais para a formulação de propostas concretas faz-se indispensável para uma escola em que a criança passa a maior parte do seu dia. Afinal de contas, a expansão da jornada escolar deve fomentar a Educação Integral em Tempo Integral dos sujeitos ali envolvidos, e não apenas a ampliação da jornada.

Compreender o lazer e formular ações para que ele se faça presente dentro da escola não tem nada a ver com uma visão romântica de educação. É papel indispensável, e diríamos ainda, inadiável, no sentido de criar mecanismos para a garantia dos direitos das crianças. Neste sentido, ao tratar essa temática na escola não nos limitamos a refletir sobre como tornar o espaço e o tempo escolar mais prazerosos, alegres, menos estressantes, mas também como fazer prevalecer a cidadania e seus direitos, tornando concreta a existência de um ambiente democrático e a vivência de seus valores, espaço para o exercício da valoração e o reconhecimento e respeito às diferenças.

Este trabalho não pretende trazer uma receita ou uma conclusão que se pretenda irretocável. A intenção é buscar reflexões que possibilitem a elaboração de propostas compromissadas a dar conta do lazer enquanto direito social e manifestação humana visando uma educação integral em tempo integral. 
Para isso, algumas categorias devem ser consideradas nessa elaboração: (1) a abordagem do lazer de maneira direta; (2) a caracterização da comunidade que contemple o mapeamento de outros espaços além dos muros escolares, assim como potencialidades culturais que a sociedade do entorno possa vir a fornecer; (3) levantamento da formação cultural das pessoas que habitam o espaço escolar para que se possam aproveitar essas potencialidades; (4) garantir o lazer em todos os componentes curriculares, criando estratégias a partir de sua especificidade concreta; (5) articular os componentes extracurriculares com a cultura local em que a escola está inserida e também (6) permitir que haja a participação dos alunos e da comunidade na escolha e desenvolvimento desses componentes.

\section{REFERÊNCIAS}

BETTI, M. Educação Física escolar: ensino e pesquisa-ação. Ijuí: Ed. da Unijuí, 2009.

BETTI, M; ZULIANI, LR. Educação Física Escolar: uma proposta de diretrizes pedagógicas. 2002. Disponível em: https://editorarevistas.mackenzie.br/index.php/remef/article/view/1363/1065. Acesso em: 3 maio 2016.

BRASIL. Estatuto da Criança e do Adolescente. Lei 8069/1990. Brasília, D.F.: Congresso Nacional, $1990 . \quad$ Disponível em: $<$ https://www.planalto.gov.br/ccivil_03/leis/L8069.htm>. Acesso em: 8 maio 2016.

. Diretrizes Curriculares Nacionais da Educação Básica. Brasília, D.F.: Ministério da $\quad 2013 . \quad$ Dducação, em: https://portal.mec.gov.br/index.php?option=com_docman\&view =download\&alias $=155$ 48-d-c-n-educacao-basica-nova-pdf\&Itemid=30192. Acesso em: 15 maio 2016.

Planejando a próxima década - conhecendo as 20 metas do Plano nacional de Educação. Brasília, D.F.: Ministério da Educação, 2014. Disponível em: https://pne.mec.gov.br/images/pdf/pne_conhecendo_20_metas.pdf Acesso em: 1 jun. 2016.




https://basenacionalcomum.mec.gov.br/documentos/BNCC-APRESENTACAO.pdf Acesso em: 5 jun. 2016.

. Decreto 7.083 de 27 de jan. de 2010. Brasília, DF, jan. 2017. Disponível em: http://www.planalto.gov.br/ccivil_03/ ato2007-2010/2010/decreto/d7083.htm. Acesso em: 21 mai. 2016.

GADOTTI, M. Educação Integral no Brasil: Inovações em processo. Disponível em: http://acervo.paulofreire.org Acesso em: 17 abr. 2016.

JUNDIAÍ (SP). Secretaria de Educação. Projeto político pedagógico da EMEB João Luiz de Campos. 2015.

A escola de tempo integral. Jundiaí, SP, SMEE, 2012. Disponível em: http://saladeimprensa.jundiai.sp.gov.br/PMJSITE/biblio.nsf/V03.01/sme/\$file/102. pdf. Acesso em: 22 mar.2016.

. Diretrizes Curriculares da Educação Básica do Município de Jundiaí (SP). Jundiaí: SMEE, 2016.

MARCELLINO, N.C. A sala de aula como espaço para o "jogo do saber". In: MORAIS, R. (Org.). Sala de aula: Que espaço é esse? 3. ed. Campinas: Papirus, 1988. p. 59-70.

. Lazer e Educação. 7. ed. Campinas: Papirus, 2000.

MARCELlinO, N. C. Pedagogia da Animação. 7. ed. Campinas: Papirus, 2005.

RIBEIRO, D. Balanço crítico de uma Experiência Educacional. 1995. Disponível em: <https://teiaufmg.com.br/wp-content/uploads/2014/07/RIBEIRO-D.-CIEPse-GPSBalan\%C3\%A7o-cr\%C3\%ADtico-de-uma-experi\%C3\%AAncia-profissional.pdf $>$. Acesso em: 18 abr. 2016.

SILVA, C.L.; SILVA, T.P. Lazer e educação física: Textos didáticos para a formação de profissionais do lazer. Campinas: Papirus, 2012.

SILVA, D.A.M. A implementação dos CEIs "Naves-Mãe" no município de Campinas e suas implicações para os direitos das crianças: um novo cavalo de Troia? - Tese de Doutorado. Programa de Pós-Graduação em Educação PPGE/UNIMEP. Piracicaba, UNIMEP, 2014.

TEIXEIRA, A. Uma experiência de educação primária integral no Brasil. Revista Brasileira de Estudos Pedagógicos. Rio de Janeiro, v.38, n.87, jul./set. 1962. p.21-33. Dísponivel em: <https://www.bvanisioteixeira.ufba.br/artigos/uma.html>. Acesso em: 21 maio 2016. 


\section{Endereço dos Autores:}

Débora Alice Machado da Silva

R. Prof. Antônio da Silveira Bueno, 58 - jardim chapadão

Campinas - SP - 13.070-159

Endereço Eletrônico: debeera@hotmail.com

Mário Hiago de Souza

Rua Salvador Vaccari, 238 - Jardim Florestal

Jundiaí - SP - 13.215-650

Endereço Eletrônico: mariohiagosouza@hotmail.com 